Association for Information Systems

AIS Electronic Library (AISeL)

Winter 12-5-2005

\title{
Introduction of 3rd Generation Wireless Services in a Multi- EnterpriseVPN Environment: Case of the Port of Rotterdam
}

\author{
L.F.J.M. Pau \\ H. Chen \\ P. van de Coterlet
}

R.A. Zuidwijk

Follow this and additional works at: https://aisel.aisnet.org/iceb2005

This material is brought to you by the International Conference on Electronic Business (ICEB) at AIS Electronic Library (AISeL). It has been accepted for inclusion in ICEB 2005 Proceedings by an authorized administrator of AIS Electronic Library (AISeL). For more information, please contact elibrary@aisnet.org. 


\title{
Introduction of $3^{\text {rd }}$ Generation Wireless Services in a Multi-Enterprise VPN Environment: Case of the Port of Rotterdam
}

\author{
L.F.J.M. Pau, H. Chen, P. van de Coterlet, R.A. Zuidwijk \\ Rotterdam School of management \\ P.O. Box 1738, 3000 DR Rotterdam, the Netherlands \\ Phone: +31 104082282 Fax: +31 104089010 \\ Email: lpau@rsm.nl
}

\begin{abstract}
The needs as well as the bottlenecks are analyzed in the deployment and use of wireless services in a networked environment of companies sharing some common supply chain processes. The specific case is the multienterprise networks around the Port of Rotterdam, researched as part a large project on value-added wireless services in this environment, sponsored by KPN Mobile. New services, operational requirements, decision processes as well as tariff and organizational problems are reported.
\end{abstract}

\section{Introduction}

This paper summarizes the main results of a large sponsored project entrusted to Rotterdam School of Management (RSM) by KPN Mobile, in collaboration with the Port of Rotterdam authorities. Its focus was on identifying drivers and bottlenecks in the usage and creation of wireless services in the Port of Rotterdam.

It also aimed at creating an understanding for the decisions and demand processes amongst port users and different groups. For the Port of Rotterdam and its partners: the goal was to have a third neutral party elicit the use of GPRS and 3G wireless services, and propose business processes making best use of basic and valueadded/customized 3G wireless services; this analysis applies to services as they exist or could be developed by the Port or its associates. RSM, in collaboration with the Erasmus Center for Maritime Economics, was in such a position to be able to extend the qualitative comparison to the identification and survey of the wireless activities at about 16 other ports worldwide.

The project was organized into three basic focused tasks addressing more specifically:

- Logistics processes and competitive impact

- Basic $3 G$ voice and data services

- New $3 G$ voice and data services

The work method used was the following. A sequence of thematic interaction sessions took place on each of the three focus tasks, aimed at eliciting key issues, opportunities and difficulties from different angles. The field work, involving each time 2-3 different RSM researchers, took place at over 80 companies or public institutions with interviews based on

Proceedings of the Fifth International Conference on Electronic Business, Hong Kong, December 5-9, 2005, pp. 200 - 206. thematic questionnaires and evaluation criteria. The interviewed parties were all at management level, which is rather exceptional. Contacts were also made with an additional set of 70 companies via questionnaires, and contacts or meetings were held with 25 companies outside the Netherlands. As to the research methodology, a systematic identification of bottlenecks and opportunities at the multi-enterprise business process level was carried out in all the three basic tasks above.

The verification and discrepancies were revealed by the interviews and common questionnaires/evaluation criteria. For lack of space reasons, this article only reports on the overall conclusions (Section 2), some of the findings and cases from the task on logistics (Section 3), before dealing specifically with New wireless services for port operations (Section 4). It continues in Section 5 with the related business models and organizational issues (Section 6). Readers not familiar with this sector are referred to [1], [2] for terminology.

This short presentation is not research focused but brings value to research on the difficulties in introducing 3G services into multi-enterprise environments. For obvious reasons there is not much academic literature on this subject, and even less on wireless operations in harbors.

\section{Context and Overall Results}

\section{1 General}

The Port of Rotterdam is economically an important worldwide logistics hub present in the Netherlands and involving many small and large companies and organizations to whom wireless operators would like to offer capabilities and services. The Port of Rotterdam holds one of the top ranks worldwide for a large number of major logistics and supply chain processes (and tops total port throughput in tonnage worldwide), the sheer diversity of which poses some significant challenges for wireless services (generic as well as value-added services). Furthermore, the largely decentralized nature of the actual operations and information flows, besides a consensus based nature of local decision making, and very tight operating budgets everywhere, make it difficult organizationally to map the demand for advanced wireless services with sufficient business revenue base. KPN Mobile asked to put the emphasis on 3G wireless services and their demand, which later expanded in the project to GPRS based services, 
inevitably revealed a significant lack of flexibility and even resistance amongst most private actors in the Port (including shipping lines) in terms of technology migration. Furthermore, most uses of wireless communication are still tied to mobile field workers who drive a bottom up adoption process, meaning that in the best case GSM, and in some rare cases GPRS, are still "good enough" and that no specific investment budgets exist for service creation or wireless information gateways.

\section{2 Logistics and Competitive Position}

For the actors inside the actual physical supply chains, as investigated as part of the focus task on "Logistics and competitive positioning”, the general finding is that there are no indications that they will adopt $3 \mathrm{G}$ on a large scale in the short term. Nevertheless, the identified logistics development trends driving the adoption of $3 \mathrm{G}$ services amongst these actors are the administrative complexity and exception handling, the migration from voice to data, and external drivers like US safety/security regulations. The bottlenecks were insufficient wireless dependability, back office and broadband fixed Internet as alternatives, and the politics and power of supply chain relationships.

\section{3 Basic Services}

For all users (service focused or physical flow focused) of generic wireless services, covered in the related focus task "Basic services", whether small and middle sized enterprises, large organizations, or those with very unique service contexts, the dominant issue is one of perceived (or observed) GPRS and 3G tariffs, as they risk to impact field operations and permanent operations which should not in their minds be charged per minute or MB. Even if public sector users may have less concern for tariffs and may be earlier adopters/pilot sites, the likelihood that their adoption will spill over to 3G services is minimal. Another important factor is that, in significant cases, the decisions to adopt GPRS or $3 G$ basic services, are not made in the Port area at all but elsewhere in the Netherlands or abroad which render local marketing of generic services ineffective. Other limiting factors are the difficulties or costs to find specialized terminals working in a dependable way in a Port context, as well as the lack of truly experienced custom mobile application integrators with logistics understanding able to develop reliable solutions.

\section{4 New Wireless Services}

The field of new wireless value-added services benefiting the Port of Rotterdam business environment is rich in concepts and interested parties, but poor on actions and players leading integrative projects for wireless information distribution, or for productivity gains. When some analysis or prototyping has been done, GPRS value added services are still preferred over 3G for the foreseeable mid-term future, not the least because too few business processes in the Port (except safety related) demand high data rates or close-to real time performance. Also, other major bottleneck factors are the lack of a single trusted neutral party for information services, and the absence of revenue based thinking as opposed to cost cutting and/or passing on costs (such as wireless services) to customers.

The comparison with other ports shows that a centralized accountable actor or a dominant user, are always factors for faster adoption of wireless services on sound cost/revenue basis, as opposed to "nice to have" basis.

The research has also shown that alternative technologies and services to 3G such as WLL, WIMAX and even $\mathrm{WiFi}$, are a real threat when driven by sound business models (such as managed services), clear trusted ownerships, and above all low costs to users, for same or better dependability and security.

\section{5 Proposed Approach}

To unlock this situation and allow for Port users to gain the benefits of 3G, the most pragmatic approach seems to involve one or two business and revenue driven focused private sector deployment initiatives of innovative services with a clear leader driven by short terms commercial benefits to just a few partners. This can very well happen if a major actor decides top-down for the productivity gains of linking better his operations in the Port with his traditional and closest suppliers or customers. Reinforcing the feasibility of this approach would be the availability of customizable tools for cost and revenue modeling of New 3G services, supplied either by the mobile operator(s) or, better, by a neutral party. Also, well publicized, and "simple to understand" tariff packages for closed subscriber groups using generic $3 G$ services, seem necessary with minimal bureaucracy/sales efforts, e.g. using subscriber self-care options. Beyond, a policy discussion should enable the framework for one party in the Port to emerge as the sole fully trusted for information collection and selective sharing, without commercial conflicts as derived from e.g. privatization.

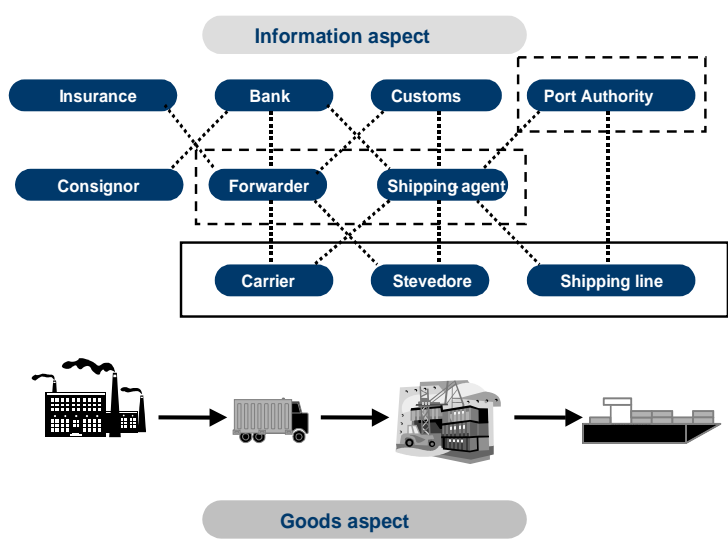

Figure 1: Information and goods views of Port interactions 


\section{Wireless Usage in Port Logistics and Supply Chains}

\section{1 Introduction}

Supply chains extend over the globe from sourcing raw materials and supply of intermediate parts and products to delivery of goods to end customers, and collection of product returns for environmentally conscious recovery and disposal. As a node in these global supply chains, the port of Rotterdam accommodates transhipment between deep-sea vessels and transport modes that service the European continent and hosts production and other value-adding services. (Figure 1)

Transport modes or means of transport are feeder, short sea shipping, barge, train, truck and pipe lines, supplemented by air cargo. The cargo varies from liquid and dry bulk to (containerized) discrete products. Next to being an enabler, the port of Rotterdam also needs to guarantee health, safety and security of cargo, traffic, industrial complexes and the city. Recent developments here are tightened food safety regulations and anti-terrorism regulations and measures.

\section{2 Administrative Complexity and Exception Handling}

Although the physical process of transhipment seems simple, the linkages between the organizations and resources involved constitute a complex network (figure 1) [3], [4]. For example, in the port area, hundreds of trucks each send out numerous messages related to (pre-notifications of) arrivals and departures at terminals, pick-up and delivery of cargo, etc. A distinction needs to be made between messages that confirm planned execution and messages that contain alerts indicating that planning could not be met. Another case is given:

\section{FIELD EXAMPLE 1: FOOD AND CONSUMER PRODUCT SAFETY AUTHORITY}

\section{Current Situation}

\section{After} an

on-

site cargo quality inspection visit by the Food \& Consumer Product Safety Authority, the cargo is either cleared for further transportati on or a sample is taken to be inspected in the laboratory at the back office. This notification is presently done by voice through a mobil e phone. After establishing contact, the planner may provide the ins pector with planning adjustments. Upon returning to the back office , the inspector is responsible for uploading (so called signingoff) the inspection data from his laptop on the computer system for further processing. Planners are, next to ensuring and adjusting smo oth inspections planning, responsible for providing the inspector wi th necessary information and giving input for the planning of labora tory activities. These activities cannot be handled efficiently under $t$ he current circumstances.

Wireless enabled vision

Forthcoming European legislation, called the General Food Law, requires import and in-transit cargo to be inspected in the country of entrance, instead of in the country of clearance. Since the Port of Rotterdam is a major port of entry for large cargo volumes with destinations all over Europe, this would result in an increase in the number and diversity of inspections, and possibly more ad hoc inspections to be conducted by the cargo quality inspectors in the Netherlands. The present staff of 10 inspectors may increase fivefold. Such an increase would make the planning of inspections and scheduling of inspectors extremely difficult. Perceived opportunity here are $3 \mathrm{G}$ services, especially when coverage in the Netherlands is assured.

\section{3 Integration of Mobile Resource Support Systems and Mobile Communication Systems}

Mobile resources such as pilots and truck drivers use electronic devices that support decision making at remote locations. When mobile communication is required, one can expect additional benefits when decision support and communication possibilities are integrated. Two field examples are summarized:

\section{FIELD EXAMPLE 2: PILOTAGE PORTABLE PILOT ASSIS TANCE (implemented by Loodswesen in Rotterdam since May 2004 using 3G and GPRS)}

\section{$\underline{\text { Prior Situation }}$}

Pilots control the boarded vessel and navigate it in a safe and efficient manner to the destination terminal in the port. Efficient and safe management of vessel traffic is highly dependent on the availability, reliability, timeliness and accuracy of data. These data are generally of three types: (1) environmental information: metrological and hydrological data (real time and forecasts), tides reporting scheme, (2) vessel information: both static and dynamic data, e.g. vessel characteristics and restrictions, to be provided to tugboat companies for towage requirements, and (3) (surrounding) traffic information: traffic density expectations, path predictions, traffic image, port and waterway infrastructure (opening times of locks, berth allocation, etc). Traditionally, the pilot relied on information by sight, voice radio communications (VHF) and radar. The information provided to the navigator originates from the vessel itself and from external sources, which is not really real-time.

Wireless enabled vision

To be able to achieve the needed improvements, the pilots are equipped with an advanced mobile device: the PPU (Portable Pilot Unit) made of a laptop with 3G data cards. The amount of data transmitted under current circumstances is $70 \mathrm{Mb}$ during a time period of several hours. The data consists of hydrological data, meteorological data and a track table or traffic image of the VTS. The pilots would like to receive additional data on reporting, passage plans, metrological data from other 'sensors', information about hazardous materials, predictions of traffic flows and traffic intensity, and meteorological and hydrological data currently 'owned' by the Port Authority. The operational trials confirmed that UMTS can provide the needed bandwidth to support these users.

3G / RFID PROTOTYPE: TRACKING CARGO STATUS VIA RFID 
For logistics service providers, applying RFID tags on goods could be useful, especially for theft-sensitive goods. Now these goods are loaded in a sealed part of the truck. With a camera in combination with RFID tags these goods could be better monitored and thus better service to the customer could be provided. Continuous matching of the RFID tag on the product with the order destination (e.g. coupled to the board computer and mobile communication) provides better security possibilities. Goods security can be made easier, also loading and unloading can go much faster in the warehouse. With RFID tags and readers, retyping of stock lists and one by one reading of barcodes is not necessary anymore. However, given the lack of global standards, the initial investments and relative high costs (e.g. compared to barcodes), as well as the needed redesign of the supply chain processes, RFID is still seen as a technology of the future by the companies interviewed., although prototypes are built .

\section{4 Bottlenecks}

\section{Legacy Systems and Projects}

Quite a few organizations in the Port are actively developing applications of IT in order to improve the performance of their logistics operations. Although this attitude may facilitate adoption of 3G, recent or on-going innovations within these organizations hinders adoption of another technology such as wireless.

\section{Back Office and Fixed Network}

Mobile resources usually need to communicate with their back office on a regular basis. However, when employees regularly have a fixed data network connection at their disposal, a mobile data connection may be redundant. Perceived security problems with mobile communication contribute to the fact that the described situation is considered satisfactory. For the same reason or for operational control, communication via back office may be preferred over direct communication between mobile resources and other organizations.

Supply Chain Relationships and Assessment and Redistribution of Benefits

Information exchange in the Port with mobile resources involves several organizations in most cases. Moreover, in order to coordinate supply chains, information needs to be integrated beyond organizational borders. Sharing of operational data meets resistance when parties do not trust each other. Because 3G mobile services are part of an interorganisational system, where data needs to be shared, this bottleneck needs to be taken into account. A clear distinction in access rights, authorisation levels and (re)distribution of benefits is needed to achieve adoption, especially in cases where one organisation needs to make the investments and the other gains the benefits.

\section{Network Scope and Coverage}

A main bottleneck is the dependability of the 3G basic service coverage. If the wireless network is not $100 \%$ reliable, the service will not be adopted. Even a low-QoS event can be disastrous for the operations performed and the revenues of Port parties. Therefore, UMTS will be an option when other parties start using it as well in an integrated manner, possibly on a port community level, which is connected to service creation and private VPN's, port authorities and partners.

\section{New Value-Added Wireless Services For Port Operations}

Although not all interviewed parties had any concrete ideas or plans, some did, and to better understand the business drivers and bottlenecks, they are mentioned here in Table 1.

\begin{tabular}{|c|c|}
\hline $\begin{array}{l}\text { NEW } \\
\text { SERVICE } \\
\text { CATEGORIE } \\
\text { S }\end{array}$ & Description \\
\hline $\begin{array}{l}\text { Generated by } \\
\text { interviewed } \\
\text { parties }\end{array}$ & 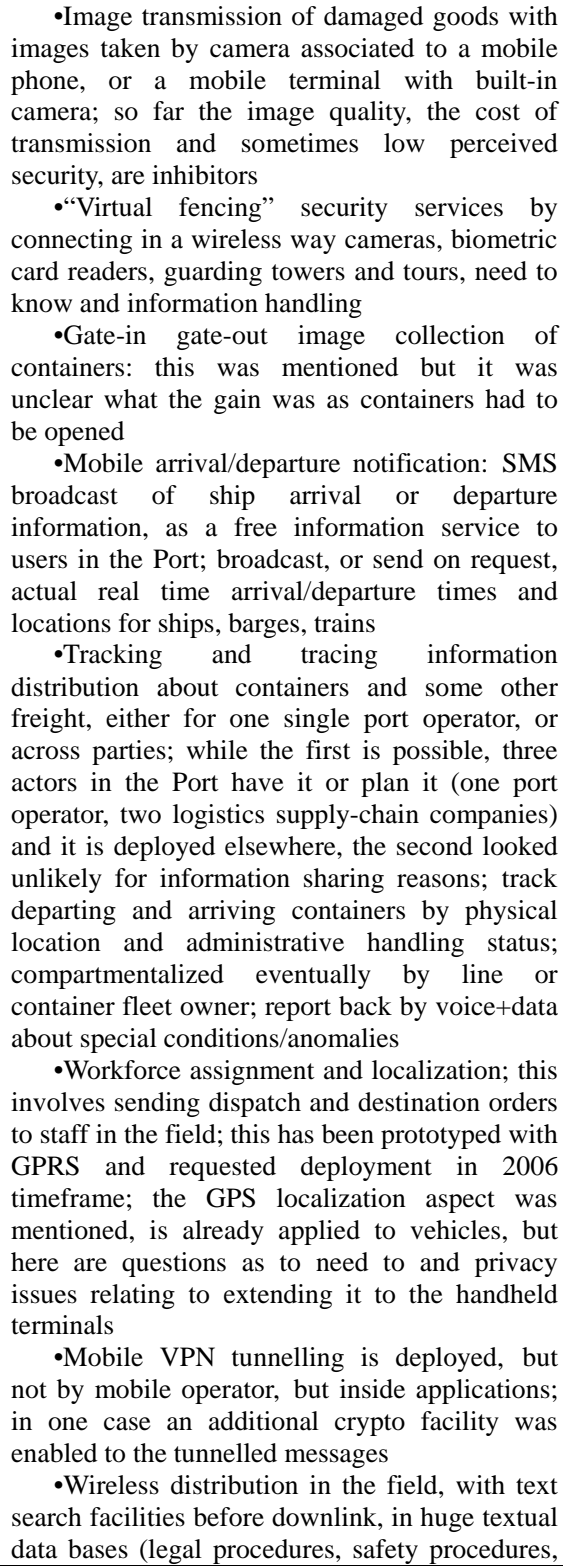 \\
\hline
\end{tabular}




\begin{tabular}{|c|c|}
\hline & $\begin{array}{l}\text { etc) } \\
\text { •Multimedia wireless dangerous goods } \\
\text { inspection with data retrieval } \\
\text { •Integrated dispatch, technical action, } \\
\text { reporting, and financial settlement in field } \\
\text { support tasks; one such system is already } \\
\text { deployed using GPRS and will stick with GPRS } \\
\text { for } 10 \text { years } \\
\text { •Maintenance logs about ship engines or } \\
\text { elements } \\
\text { •Passenger lists } \\
\text {-Ship or vessel location services, for both port } \\
\text { operations as well as for ship passengers }\end{array}$ \\
\hline $\begin{array}{l}\text { Generic } \\
\text { services }\end{array}$ & $\begin{array}{l}\text { •Managed VoWi voice over WLAN hot spot } \\
\text { areas, in areas where voice traffic intensity } \\
\text { would yield to high costs if } 3 G \text { was used; } \\
\text { interoperability with } 3 G / P S T N /(i n \text { future: VoIP) } \\
\text { wide coverage basic services } \\
\text { •IP-to-PSTN breakout service to pipe voice } \\
\text { calls across a company or home office or home } \\
\text { WLAN network } \\
\text { •Picture data archive filing and management } \\
\text { service, with batch sorting / compression } \\
\text { /indexing / distributed access control }\end{array}$ \\
\hline $\begin{array}{l}\text { Content/infor } \\
\text { mation } \\
\text { distribution } \\
\text { based new } \\
\text { services }\end{array}$ & $\begin{array}{l}\text { •Distribution of long-term agreements and } \\
\text { tariffs to shipping lines' account managers while } \\
\text { meting customers; this service is rivaled by } \\
\text { Internet access and put back by the need to } \\
\text { handle paper copies } \\
\text { •Generic customizable wireless staff } \\
\text { dispatching application: Staff and special } \\
\text { equipment/ vehicle dispatching orders and } \\
\text { acknowledgments; organized by domains and/or } \\
\text { terminals } \\
\text { •Fleet management application with content } \\
\text { managed by fleet owners and operators }\end{array}$ \\
\hline $\begin{array}{l}\text { Business } \\
\text { process } \\
\text { support }\end{array}$ & $\begin{array}{l}\text { •Exception alarms sent by SMS; this was } \\
\text { mentioned, but not in a specific application } \\
\text { context, and is/can be handled without a value- } \\
\text { added application if data entry (voice or } \\
\text { message) are made easy } \\
\text { •Accident insurance claim evidence and } \\
\text { reporting assembly and distribution, including } \\
\text { multimedia evidence } \\
\text { •Cleaning/refueling/resupply/personnel } \\
\text { landing/etc. information dispatch service for a } \\
\text { specific ship arrival across company } \\
\text { partnerships } \\
\text { •Emergency service coordination (fire- } \\
\text { fighters, security, police ) on Port premises, with } \\
\text { pushed-down info about vehicle/ship/truck }\end{array}$ \\
\hline
\end{tabular}

Table 1: New service ideas generated

The only prior Pilot at the Port of Rotterdam was a Customs X-ray container scan with wireless transmission of scanned images. Although a feasibility prototype was built for the Port of Rotterdam Customs in 2001, with GPRS for image transmission and resulting productivity gains, this was never put in service because the transmission time of the huge image files was too long; this would not change much with 3G.

\section{Business Factors and Models for Adoption of New Wireless Services in Port Operations}

The main business drivers for ideas and concepts of new services were:

a. information services benefiting eventually organizational capabilities and flexibility

b. outright productivity gains linked to faster and acceptable mobile access to employees, thus reducing physical transport, in a way similar to mobile field support operations; to this category belong ship and goods inspection and field support tasks, which both have significant volumes of process instances (typically 8000 task instances/year and higher); GPRS or 3G effective data speeds were a gain, but far less important than the gains obtained by the sheer wireless access and its end consequence of speeding up in the field the different work procedures

Surprisingly enough, in the first category a) no business or revenue models were envisaged in a clear way to recoup the cost of development and operations of such new wireless information services; this effect is not due to the analysis method at all, but to another factor discussed below. The major concern was more one of control and influence. In terms of cost, all were looking to "Port (authority) money" to cover expenses, stating that these costs would be merged inside handling fees paid by the ships. In this first category a), an underlying issue with both positive and negative outcomes on business adoption, is the question of which is "the most trusted", or the "best trusted" party for information collection and distribution. If one such party emerges and is accepted in this role, new services of type a) may be deployed and adopted widely.

In the second category b), and if the existing services to be enhanced existed already with their organization, the major concerns were dependability and costs. Apparently, the perception is that 3G new services "may not work", especially as eventual GPRS based forerunners already have dependability problems. In other words, users want services which "work" and not "wonders".

The net effect of the effects discussed above for a) and b) type new services, is that those persons or groups spelling out in clear terms the business gains from 3G new services, are generally been seen as "dreamers", and adopters will "scale back" the ambitions to at best GPRS and sometimes even value added GSM services. An example thereof, is the ultimate preference of the owners of 3G Pilot at Loodswezen (supported by KPN Mobile) to use GPRS instead of 3G, as "GPRS is good enough" (as in other harbours with the same application).

\section{Organizational Factors and Bottlenecks around New Wireless Services}

By far the overriding bottleneck was the organizational framework for wireless new services (GPRS and 3G) in the Port of Rotterdam in the private sector. The factors of this restriction are varying mixes of: 
-A: the complete lack of easily customizable cost and revenue models for new $3 \mathrm{G}$ services

-B: absence of actual operational leadership, contrasting the multitude of wishes to "get involved"; this is of course linked to the fact that no specific budget is yet proposed or approved in any umbrella or public organization catering to the private sector companies operating in the Port. Any new GPRS/3G service will involve content/data sources, content/data owners, service developer (engineering), service developer (business), operations and management, revenue and cost aggregation, and last (but not least) wireless infrastructure owner. But who will be the project owner and project manager? All parties interviewed realize this bottleneck and point at the Port of Rotterdam Authority, but do not see any decisive leadership from it yet, as the Port Authority has many more pressing issues to handle

-C: the investment reluctance of most private sector companies to carry out service creation and trials together with other parties; the noticeable exception are some select few shipping lines or international container handling operations which have, or plan to have soon, global wireless operators contracts alike those they have for satellite communications.

-D: in the context of interoperability: the absence of any single body able to impose basis IT, or wireless application interface standards (PARLAY etc), application integration standards (XML, CORBA, OMA...), and document format standards for new services; the result is the risk for lack of interoperability and higher new service application integration costs.

-E: some degree of traditional mistrust as to disclosing some information about ships or containers to third parties; even in terms of the definition, establishment and management of closed user groups, mistrust is present

For governmental organizations, the first remark A) also applies, due to the multiplicity of stakeholders: Ministry of Transport, Ministry of Finance, Ministry of Agriculture, Ministry of the Environment, Ministry of Economics, Ministry of the Interior, EU Directorate general Enterprises, and finally the Port of Rotterdam Authority at a lower level. The deployment of new wireless services might be linked to a government transactions portal initiative, where there is an appointed leader: Ministry of Finance.

Another bottleneck for new service deployment is one due ultimately to cultural roots associated with physical transport, and not valuing information assets or the business processes around information handling. The consequence is in the Port of Rotterdam that, whereas in some other ports the new service owners and/or operators get also revenue from new services, these services are in Rotterdam considered at best as a cost item, the cost value of which must be minimal and bundled together with other services, some of which perceived to be more urgent than wireless services. As one institution said: "highest priorities are inhouse systems, followed by Internet services and with later future plans for new wireless services”. Another facet of the same culture is that "repeated simple processes are profitable, and flexible ones are expensive”.

In addition, and mentioned by some interviewed parties, the perceived total costs and tariffs for new services are dissuasive in the private sector, although the public sector operational divisions do not seem to be concerned. For almost all interviewed parties from the private sector, they considered that GSM data was far too expensive, GPRS was too expensive, and 3G also; they wished tariffs which, for same data amounts and QoS, should cost the same as on a corporate LAN (Ethernet or WiFi), with data flow reductions outweighed by mobility/ubiquity gains.

Whereas CDMA-2000 and DAB were not mentioned, WiFi, WLL and WIMAX were indeed seen by over ten interviewed parties as a way to achieve lower costs and independence from public 3G operators. Around WLL, a consortium including a power utility (which was granted a 12 years WLL license), a security company, an equipment vendor and some partners, have assembled a consortium aiming at offering managed video based security services for any party in the port. Some of the consortium members are already the largest GPRS users in the Netherlands, and have deployed segment specific GPRS based VPN solutions, besides their staff has been familiarized already with mobile capabilities. The managed service could be offered by this consortium to the Port Authority, which would then sell managed services as a proxy for a supplier consortium, or by the consortium if it got the license and a legal structure. It should be highlighted that the concept of a managed service relieves the end user from up front investments and operations, and allows this end user to "pass on" the cost to his own customers without loading the balance sheet. WLL can also be considered as an access media for on-site cameras etc with a significantly better bandwidth and transmission cost than 3G. Finally should also be mentioned that what brought these parties together was a top-down business concept, i.e. compliance with the ISPS security codes and procedures across the Port of Rotterdam. This consortium is one of the very rare ones to have taken seriously the issue of revenue as well as costs. They also see as a business driver the fact that their customers will perceive that the service supplied is managed for them, the users.

\section{Conclusions}

While other such cases exist, such as in the oil and automotive sectors [5], multi-enterprise wireless VPN's demand first organizational and trust issues to be addressed, then costs, and only finally the technical capabilities.

\section{References}

[1] P. Brodie, Dictionary of Shipping Terms, 4th Ed., December 2003. (http://click.cminteractive.com/?1f6rnjXrE=407558)

[2] Z. Oya, Port State Control, 2nd Edition, 2004 www.informalaw.com/port 
[3] J. van Hillegersberg, J. Tseng, R. Zuidwijk, M. Edelman, D. van Hof, M. van Oosterhout, J. van Nunen, "Hub to Higher Performance? An Internet Hub for the Vos Logistics Supply Chain”, in "Intelligent Logistics Concepts”, Thierry Verduijn, Babiche van de Loo (eds.), Eburon, Delft, 2003, pp 45-76.

[4] S. Chopra, P. Meindl, Supply Chain Management, Pearson Education, Upper saddle River NJ (2004).
[5] L-F Pau, M.H.P. Oremus, "WLAN Hot Spot services for the automotive and oil industries: a business analysis" Or: "Refuel the car with petrol and information, both ways at the gas station", General Motors Institute/Kettering University University Synergy Program (USP) International Conference. Collaborative Industry Supply Chain and Mobile Commerce - emphasis on the automotive industry, 15 - 18 September 2003, Dearborn, Michigan 